\title{
Using mRNA to investigate the effect of low-pressure ultraviolet disinfection on the viability of $E$. coli
}

\author{
Chao Yang, Wenjun Sun (凶), Xiuwei Ao
}

School of Environment, Tsinghua University, Beijing 100084, China

\begin{abstract}
H I G H L I G H T S
- UV can induce damages on mRNA consistently among different genes.

- SOS response was more active after UV treatment.

- Programmed cell death was not found to be more active after UV treatment.
\end{abstract}

\section{A R T I C L E IN F O}

Article history:

Received 27 December 2018

Revised 21 February 2019

Accepted 22 February 2019

Available online 18 March 2019

Keywords:

UV disinfection

Viability

mRNA

SOS response

Programmed cell death

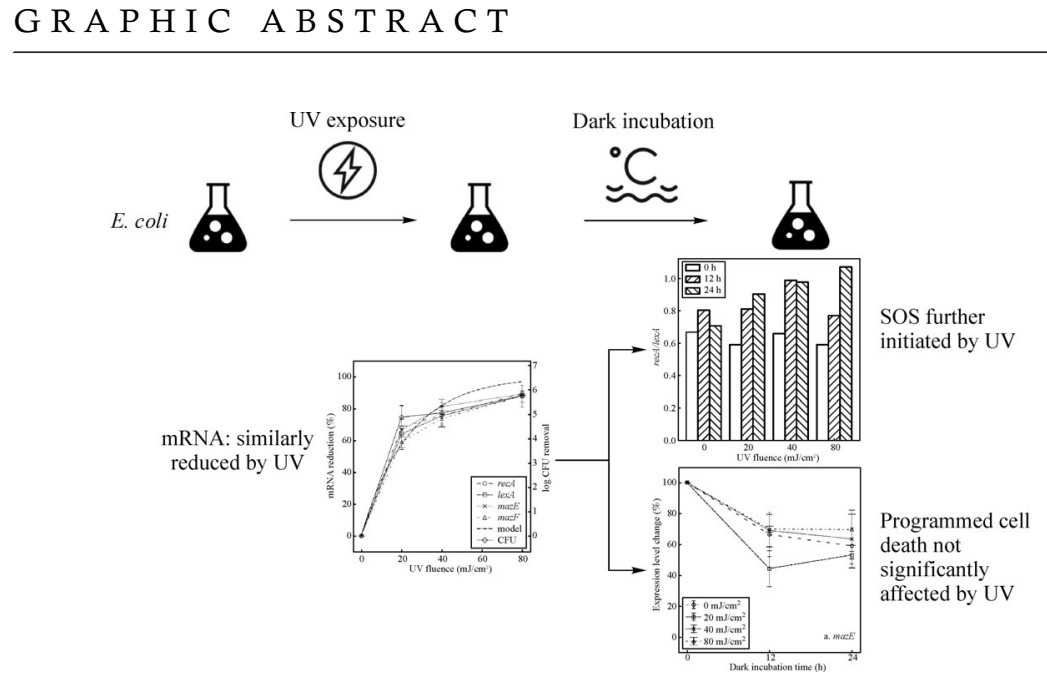

A B S T R A T

The efficacy of ultraviolet (UV) disinfection has been analyzed and validated by numerous studies using culture-based methods, yet the discovery of the viable but nonculturable state necessitates the investigation of UV disinfection based on viability parameters. Paired regulators of the SOS response system, recA-lexA, and the programmed cell death system, mazEF, in Escherichia coli were chosen as the target genes, and the effect of UV irradiation on the mRNAs of the four genes was studied. This research showed that, after UV irradiation, the responses of the mRNAs were highly consistent, with reduction percentages of approximately $60 \%$ at $20 \mathrm{~mJ} / \mathrm{cm}^{2}, 70 \%$ at $40 \mathrm{~mJ} / \mathrm{cm}^{2}$, and $90 \%$ at $80 \mathrm{~mJ} / \mathrm{cm}^{2}$, and these reductions were believed to be the result of direct UV damage to nucleic acids. After $24 \mathrm{~h}$ of dark incubation, recA and lexA were both upregulated but to a lesser extent for repressor lexA; and $m a z E$ and $m a z F$ were both downregulated. This result implies that UV irradiation induces the dark repair system more actively, and the cells will proceed to death at a rate similar to that associated with natural decay.

(C) Higher Education Press and Springer-Verlag GmbH Germany, part of Springer Nature 2019

\section{Introduction}

Ultraviolet (UV) is a band of light whose wavelength ranges from 10 to $400 \mathrm{~nm}$, and has been studied in many environmental-related areas, including environmental biochemistry (Wang et al., 2017), disinfection and advanced oxidation ( $\mathrm{Lu}$ et al., 2018). UV disinfection is one of the

Corresponding author

E-mail: wsun@tsinghua.edu.cn more established and promising water sterilization advancements, with a predominantly favorable performance against protozoan parasites (Craik et al., 2000; Belosevic et al., 2001) and a negligible impact on the formation of disinfection byproducts (Reckhow et al., 2010), whereas technologies using conventional oxidative chemical disinfectants encounter problems in these two areas (Liu et al., 2017; Wang et al., 2018). The advantages come specifically from its distinctive germicidal mechanism. Nucleic acids have high absorbance for UV light, and this absorption leads to their development of photochemi- 
cal lesions. As the most important biomolecules, these lesions on nucleic acids will hinder the proliferation of microorganisms (Hijnen et al., 2006). The two most essential types of UV-induced damage are cyclobutane pyrimidine dimers $(75 \%)$ and $(6-4)$ photoproducts $(25 \%)$ (Sinha and Häder, 2002). Although numerous microorganisms have photorepair and dark repair systems to neutralize this damage (at least partially), the repair systems are not expected to fundamentally influence the efficacy of UV disinfection for drinking water, because the validated UV dose for any reactor has accounted for dark repair, and the water usually remains enclosed in a dark space after UV treatment, such as a distribution system, which conveniently prevented photo repair (Pirnie et al., 2006; ZimmerThomas et al., 2007).

The broad-spectrum disinfection performance of UV technology has been historically validated by numerous scientific studies and has a track record of safe public health practice worldwide (Blatchley et al., 2001; Zimmer and Slawson, 2002; Lehtola et al., 2003; Guo et al., 2009; Murray et al., 2015). The rationale on which a majority of these and other disinfection studies were based is that the number of pathogenic microorganisms can be well represented by the culturable organisms of their own group. Most of the "inactivated" cells that lose the capacity to replicate are assumed to proceed to natural death. However, the discovery of a microbiological phenomenon called the viable but nonculturable (VBNC) state (Xu et al., 1982) suggests that this assumption should be reconsidered. VBNC cells are not detectable by conventional culture techniques but retain various traits of viable cells (Oliver, 2000). As for UV disinfection, the traits of viable cells, including their respiration rate (Blatchley et al., 2001), adenosine triphosphate levels (Xu et al., 2018), and membrane permeability, are rarely directly affected (Nie et al., 2016), especially if the traits are measured immediately after UV treatment. Although they were inactivated by UV and can not be cultured, these cells should maintain their viability, at least to a certain extent, before their natural death. Compared to other non-growing states, including sporulation, persistence, and dormancy, the VBNC state is understood as a more universal strategy for cells to survive under adverse environmental circumstances (Pinto et al., 2015). The universality of this phenomenon should arouse interest in examining the efficacy of disinfection technologies because the disinfectants may act as the "adverse circumstances" and induce cells into this state rather than effectively inactivating them. In terms of UV disinfection, this may be especially likely because of its mechanism of damaging the nucleic acids with no minimum direct interruption of other cellular functions. Indeed, a published report of UV inducing Escherichia coli and Pseudomonas aeruginosa into the VBNC state (Zhang et al., 2015) was followed by comments expressing concern about the suitability of the experimental design and data interpretation (Gehr, 2015; Linden et al., 2015; Blatchley et al.,
2017). It is essential to choose reasonable experimental techniques and appropriate data interpretation methods when conducting research on UV disinfection. For example, UV was not considered a favorable technology with regard to Cryptosporidium parvum and Giardia lamblia until techniques dependent on infectivity were used (Blatchley et al., 2017). The methods targeting the damages induced by oxidative disinfectant but not UV, for example membrane damage, especially need to be avoided.

To investigate how UV-irradiated cells respond to damage, this study used mRNA as the indicator of cell viability. Compared to other suggested viability indicators, mRNA is theoretically more suitable for UV disinfection, as its generation is considered a trait of viable cells, and its half-life is on the scale of minutes. Additionally, changes in specific cellular functions can be indicated by the expression levels of the corresponding mRNAs. This may provide a better understanding of the UV disinfection mechanism. Two systems related to DNA damage were measured in this research: the SOS response system and the programmed cell death (PCD) system.

The SOS response system is a DNA damage-inducible system consisting of more than 20 genes encoding a network that uses multiple cellular functions to respond to DNA damage (Jungfer et al., 2007). One of the most studied processes is the dark repair system, which uses an excision repair mechanism to replace damaged DNA (Sinha and Häder, 2002). However, in cases where the damage is too severe, an extreme response can be induced in this system, causing membrane depolarization and leading to apoptosis-like death (Erental et al., 2014). The SOS response system is mediated by a set of paired genes, recA and lexA. The LexA protein encoded by lexA is the repressor of the system and binds to the promoter, preventing activation of the system under normal conditions. When DNA damage occurs, the RecA protein encoded by recA forms a complex with the single-stranded DNA resulting from the damage, inducing LexA cleavage and, subsequently, the SOS response.

During PCD, the cell initiates a certain coded intracellular process that leads to its own death (Allocati et al., 2015). This phenomenon was originally believed to occur only in multicellular organisms, but it was later found in unicellular organisms as well (Bayles, 2014). PCD has several mechanisms of action, and one of the most comprehensively studied mechanisms in bacteria is known as the "toxin-antitoxin" system (Erental et al., 2014). This system involves a pair of genes whose expressions are responsible for a toxin that can cause cell death and the generation of an antitoxin that impedes this lethal effect, respectively. As the toxin is usually stable, whereas the antitoxin is not, the cell must continuously produce the antitoxin to neutralize the toxin. One of the best known PCD systems is the mazEF pair in E. coli in which $m a z F$ encodes the toxin and mazE encodes the antitoxin (Hazan et al., 2004). 
This study investigated the UV dose-response of mRNA and examined how E. coli responded to UV disinfection with the SOS response and the PCD systems. This work explores the frontier of interpreting the changing direction of bacterial viability after UV irradiation based on mRNA measured by reverse transcription quantitative PCR (RTqPCR) and provides insight into cellular function expression in response to UV damage.

\section{Materials and methods}

\subsection{Bacterial propagation and enumeration}

E. coli K12 (ATCC \#29425), which was used as the representative organism to assess the effectiveness of water disinfection, was cultivated in tryptic soy broth (TSB) (Fisher Scientific, Suwanee, GA, USA) at $37^{\circ} \mathrm{C}$ with shaking at $120 \mathrm{r} / \mathrm{min}$ for $16 \mathrm{~h}$ until the stationary phase. The cells were then centrifuged at $5000 \mathrm{r} / \mathrm{min}$ at $4^{\circ} \mathrm{C}$ for 10 min and resuspended in standard phosphate-buffered saline (PBS) whose $\mathrm{pH}$ is 7.4 with $0.01 \%$ Tween 80 . The collection and washing were repeated twice to prepare a stock of cells of approximately $10^{8} \mathrm{CFU} / \mathrm{mL}$. The stock was refrigerated and diluted 100-fold in PBS with $0.01 \%$ Tween 80 for the following UV irradiation experiments; therefore, the microbial samples for experiments were approximately $10^{6} \mathrm{CFU} / \mathrm{mL}$. The UV absorbances of the samples at $254 \mathrm{~nm}$ were measured before irradiation for the purpose of exposure time calculation.

E. coli were enumerated as colony-forming units. Samples with concentrations below $100 \mathrm{CFU} / \mathrm{mL}$ were measured using the pour plating technique in triplicate; samples with concentrations over $100 \mathrm{CFU} / \mathrm{mL}$ were measured using the spot plating technique with 10 replicates.

\subsection{UV irradiation and dark incubation}

UV irradiation experiments were conducted with a collimated beam apparatus following the widely recognized standardized bench-scale protocol (Bolton and Linden, 2003). The setup consisted of two parallel $40 \mathrm{~W}$ low-pressure mercury lamps (Sankyo Denki Co. Ltd., Japan). The lamps were mounted horizontally on an aluminum alloy box and turned on at least $30 \mathrm{~min}$ before measurements and experiments. The box had two vertically aligned circular apertures for UV light to pass through, and the vertical distance between them was $\sim 30$ $\mathrm{cm}$. Under the beam, a stir plate was used to continuously stir the samples for homogeneity. The UV intensity distribution on the level of the sample surface was measured with an IL-1700 radiometer equipped with an SED 240 detector (International Light, Peabody, MA, USA); the irradiance at the center of the sample surface ranged from 0.147 to $0.160 \mathrm{~mW} / \mathrm{cm}^{2}$; the Petri factor described by the protocol was measured to be 0.98 . The UV fluences to which the samples were exposed were 20, 40 , and $80 \mathrm{~mJ} / \mathrm{cm}^{2}$, and the exposure times were calculated according to the standard protocol.

Irradiations were conducted at room temperature. In each exposure, $40 \mathrm{~mL}$ of the sample was prepared in a $90-$ $\mathrm{mm}$ Petri dish with a small sterile magnetic bar. With the exception of during UV irradiation, the samples were always kept in the dark to limit the effects of other light sources. Two independent UV irradiation experiments were conducted for each UV dose.

Dark incubation was performed to investigate the expression level changes of the SOS response and PCD systems. Samples were stored in $50-\mathrm{mL}$ capped centrifuge tubes with shaking at $100 \mathrm{r} / \mathrm{min}$ at room temperature.

\subsection{RNA extraction and reverse transcription (RT)}

We used $80 \mathrm{~mL}$ of sample for each UV fluence and dark incubation time point. Bacteria cells were collected with $0.22-\mu \mathrm{m}$ membrane filtration, and the membrane was then put into a $2-\mathrm{mL}$ capped tube with $0.5 \mathrm{~mL}$ pre-added RNAprotect Bacteria Reagent (Qiagen, Germantown, MD, USA). The tube was vigorously shaken for $5 \mathrm{~min}$ by a bead beater (Mini-Beadbeater-16, BioSpec, Bartlesville, OK, USA) to help with the separation of the cells from the membrane. The membrane was then carefully removed, and the procedure provided by the manufacturer of the RNA protecting reagent was followed. The RNeasy Mini Kit (Qiagen) was used to extract and purify total RNA. The RNA concentration of each sample was quantified using a UV spectrophotometer (Nano Drop 1000, Thermo Fisher Scientific, Wilmington, DE, USA). After quantifying the concentration, we mixed $4 \mu \mathrm{L}$ of the RNA sample with 1 $\mu \mathrm{L}$ of random primer and immediately reverse transcribed using the ImProm-II ${ }^{\mathrm{TM}}$ Reverse Transcription System (Promega, Fitchburg, WI, USA) following the procedure provided by the manufacturer, with annealing for $5 \mathrm{~min}$ at $25^{\circ} \mathrm{C}$ and extension for $1 \mathrm{~h}$ at $42^{\circ} \mathrm{C}$. The reverse transcriptase was thermally inactivated at $70^{\circ} \mathrm{C}$ for 15 min after the extension.

\subsection{Quantitative PCR (qPCR)}

Primers for the two pairs of genes of interest, recA-lexA and $m a z E F$, were designed using the Integrated DNA Technologies Primerquest Design Tool and are listed in Table 1. qPCR was performed to analyze the copy amounts of recA-lexA and mazEF mRNA in the cDNA sampls. The qPCR reagent is SsoFast EvaGreen Supermix (BioRad, Hercules, CA, USA). The reaction volume contains $1 \mu \mathrm{L}$ of cDNA template and $7.5 \mu \mathrm{L}$ of Supermix reagent. The final concentrations of forward and reverse primers are both $500 \mathrm{nM}$. RNase/Dnase-free water was used to make working solutions of primers and form a $15-\mu \mathrm{L}$ total reaction volume. All amplification reactions were dupli- 
cated by using an MJ MiniOpticon Real-Time PCR system (BioRad). The cycling conditions were set by following the manufacturer's instruction, which started with a $30 \mathrm{~s}$ of enzyme activation at $95^{\circ} \mathrm{C}$, followed by 40 cycles of denaturing $\left(95^{\circ} \mathrm{C}, 5 \mathrm{~s}\right)$, annealing and extension $\left(65^{\circ} \mathrm{C}, 10\right.$ s), and ended with a melting curve ramping from $65^{\circ} \mathrm{C}$ to $95^{\circ} \mathrm{C}$.

The DNA standards were the conventional PCR products of genome DNA using the same primer sets described in Table 1, which were purified with the QIAquick PCR Purification Kit (Qiagen). The molar concentrations of the DNA standards were quantified by a Qubit Fluorometer using a Qubit dsDNA HS Assay Kit (Life Technologies, Carlsbad, CA, USA). The number of copies of the DNA standards were calculated using Avogadro's number. Standard curves were run each time using 10-fold dilutions of the produced standards. The calculated copy numbers were normalized to the RNA concentration of the corresponding sample.

\section{Results and discussion}

\subsection{Immediate effect of UV on mRNA and CFU}

The mRNAs of four genes from samples treated with UV irradiation without dark incubation were probed by RTqPCR and compared to those from untreated samples to illustrate how UV damages mRNA. The absolute copy numbers of each gene were normalized to the RNA concentration and used for calculation; they are reported as reduction percentages $\left(1-N / N_{0}\right)$ in Fig. 1. The reduction was very consistent among the four genes, at $60 \%-70 \%$ at $20 \mathrm{~mJ} / \mathrm{cm}^{2}, 75 \%-80 \%$ at $40 \mathrm{~mJ} / \mathrm{cm}^{2}$, and $90 \%$ at $80 \mathrm{~mJ} /$ $\mathrm{cm}^{2}$, considering the standard deviation is about $5 \%$. A similar result was observed for $16 \mathrm{~S}$ rRNA (data not shown); as this indicated that rRNA was also affected by UV, housekeeping genes were not used in this research. This result demonstrates that if mRNA damage were measured immediately after the UV irradiation, the response curves of different genes would be highly similar, indicating that the damage occurs via similar mechanisms rather than by downregulation of any gene.

The reduction of mRNA has two possible mechanisms: UV damage or degradation in non-viable cells. The assumption is that the reduction is due to UV damage. To test this assumption, an experiment was designed to minimize the effect of degradation by using a protection reagent and performing the RNA extraction and RT immediately after UV exposure. Next, a model was developed in accordance with the mechanism of UV damage to mRNA, and the data were fitted to the model to test whether this mechanism could explain the response curve. In reference to the theoretical framework developed by (Pecson et al., 2011), the number of damaged nucleotides, $n$, follows a Poisson distribution. The parameter $\lambda$ of the Poisson distribution is both the average number and the variance of damaged nucleotides:

$$
P(n, \lambda)=\lambda^{n} e^{-\lambda} / n ! .
$$

If it were further assumed that $\lambda$ had a linear correlation with UV fluence, then the proportion of damaged mRNA could be described as:

$$
1-N / N_{0}=1-P(0, \lambda)=1-e^{-k^{*} U V \text { fluence }} .
$$

The data of all four genes were used to fit the model, and the parameter $k$ was found to be 0.0426 based on the principle of least squares $\left(R^{2}=0.965\right)$; the model is shown in the graph as the dotted-dashed line. The reasonable correlation indicated that the mRNA damage was accounted for by the direct damage.

The UV dose-response curves for $E$. coli based on CFU are also shown in Fig. 1. Inactivation reached $4.89 \mathrm{log}$ $\mathrm{CFU}$ at $20 \mathrm{~mJ} / \mathrm{cm}^{2}, 5.06 \log \mathrm{CFU}$ at $40 \mathrm{~mJ} / \mathrm{cm}^{2}$, and 5.75 $\log \mathrm{CFU}$ at $80 \mathrm{~mJ} / \mathrm{cm}^{2}$. By the standard of culturability, UV is highly effective for inactivating bacteria, and this is consistent with other studies (Zimmer and Slawson, 2002; Guo et al., 2009; Fang et al., 2014). It is worth noting that, despite the similarity in shape between the mRNA reduction response curve and CFU removal (shown in the Fig. 1 as a reference), the two are at a linear and a log scale, respectively, and must be interpreted appropriately. Although the response curve of mRNA can be explained by the aforementioned model, the tailing phase of the log CFU removal curve is believed to be due primarily to the aggregation of bacteria cells (Parker and Darby, 1995).

\subsection{The SOS response system after UV treatment}

To analyze how the cells respond to UV irradiation, samples treated with different UV doses were incubated in a dark environment for 12 and $24 \mathrm{~h}$ to monitor the expression level shift. The normalized mRNA copy

Table 1 Target genes and primers used in this study

\begin{tabular}{lcc}
\hline Target gene & Primer sequences (F/R) & Product size (bp) \\
\hline recA & GGCTGAATTCCAGATCCTCTAC/ CTACGCCTTCGCTATCATCTAC & 266 \\
lexA & CTGTTGCAGGAAGAGGAAGAA/ CCAGCAAGTCACCATCCATAA & 193 \\
$m a z E$ & GTTAATGCAGGCGCTCAATC/ GTCGATATTCTCGTGGAGGTTT & 157 \\
$m a z F$ & AGCCGATACGTACCCGATA/ AGGAACACACAGACACATACC & 144 \\
\hline
\end{tabular}




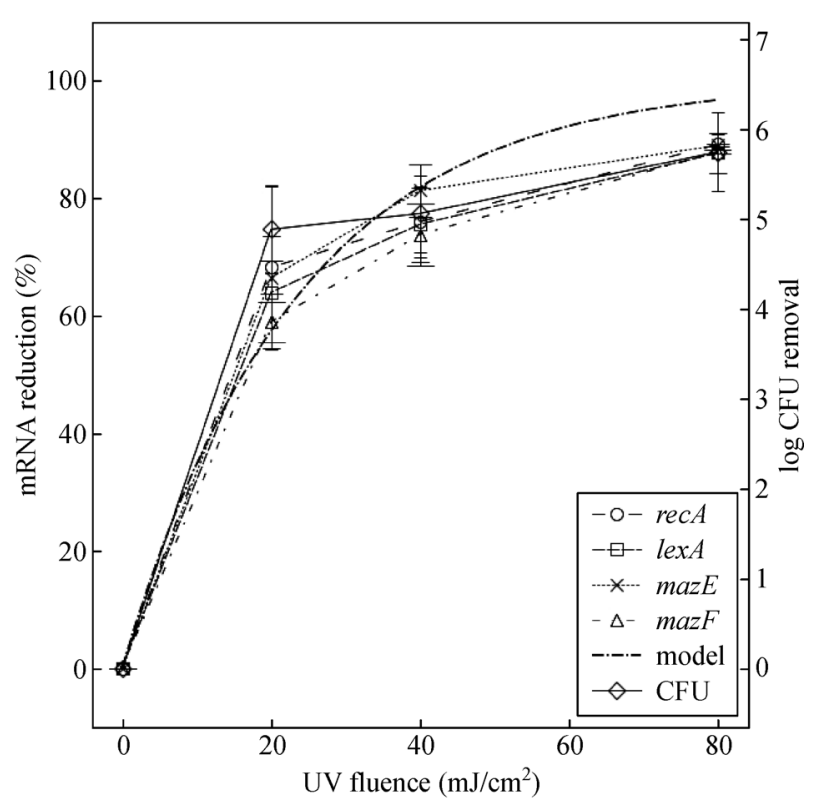

Fig. 1 UV dose-response curves of recA, lexA, mazE, and $m a z F$ mRNAs. The dotted-dashed line is an exponential model fitted from mRNA reduction data, and the dashed line with diamonds is the UV dose response of $\log$ CFU removal.

numbers at different incubation time points were compared with those determined immediately after UV irradiation, and the expression level changes $\pm \mathrm{SD}$ of both recA and lexA are reported in Fig. 2.

In all samples (both treated and untreated), the expression levels of both $r e c A$ and lexA were upregulated. However, for lexA, the expression levels of the untreated samples were upregulated to a greater extent than were those of the treated samples, and this was more distinctive at $24 \mathrm{~h}$. Due to the volatile nature of mRNA and the related experimental difficulty, the uncertainty of the results was

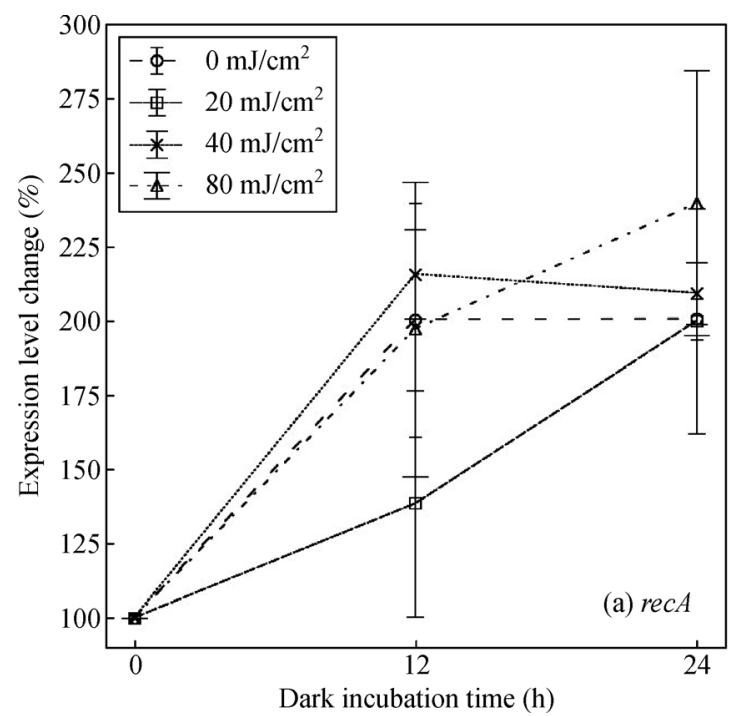

admittedly high. Therefore, we were unable to observe significant differences between samples irradiated by different UV fluences, as confidence intervals of different data points were largely overlapped.

Considering that recA and lexA work as a pair to properly function as the initiators of the SOS response system, the recA/lexA ratio was determined and is shown in Fig. 3. The unirradiated samples had ratios between 0.6 and 0.8 throughout dark incubation, and the longer incubation time did not lead to a higher ratio. The ratio in the irradiated samples showed a steadily increasing trend for each UV fluence; at $24 \mathrm{~h}$, the ratio was positively correlated with UV fluence, reaching 0.90 at $20 \mathrm{~mJ} / \mathrm{cm}^{2}$, 0.98 at $40 \mathrm{~mJ} / \mathrm{cm}^{2}$, and 1.07 at $80 \mathrm{~mJ} / \mathrm{cm}^{2}$.

This result suggests that bacteria activate the SOS response system after UV irradiation. The expression of recA in E. coli did not appear to be more active compared to that in the unirradiated samples, but the upregulation of lexA was slowed. This may result in insufficient LexA protein synthesis, allowing RecA to cleave more efficiently, thereby further initiating the SOS response system. By contrast, another study that measured $r e c A$ expression after UV irradiation and did not use housekeeping genes for normalization (Xu et al., 2018) suggested that $r e c A$ was shut down after the UV irradiation, which is not consistent with the results of this study. According to the proposed paradigm in this study, the shutdown of $r e c A$ could be due to direct UV damage, as described in section 3.1.

\subsection{The PCD system}

The PCD system response was investigated in a manner similar to that described for the SOS response system. Unlike the two regulators of the SOS response system, the expression of both regulators of the PCD system was downregulated as presented in Fig. 4. The mazE, which is

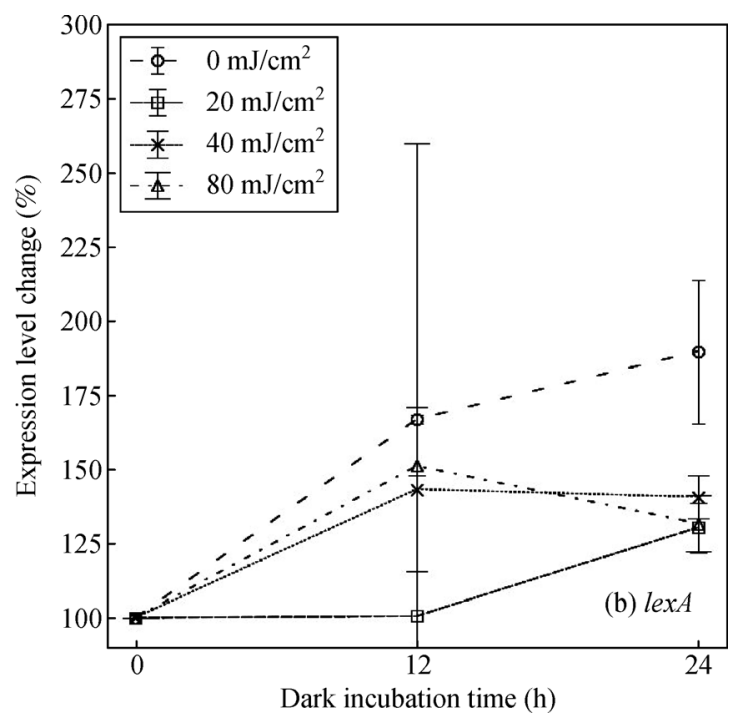

Fig. 2 Expression level changes of SOS system genes after dark incubation: (a) recA; (b) lexA. 


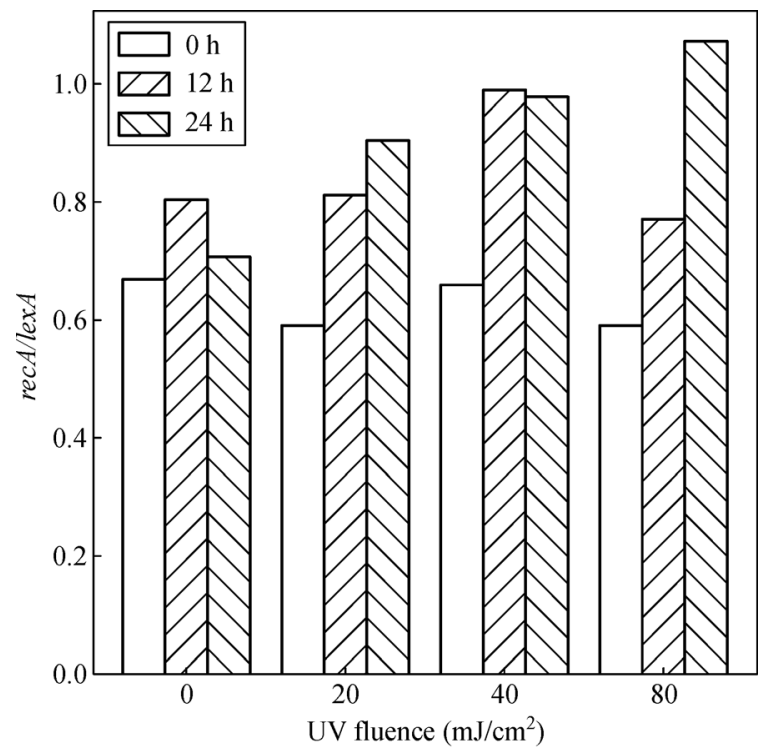

Fig. 3 Expression level ratios of recA/lexA at different UV fluences and dark incubation times.
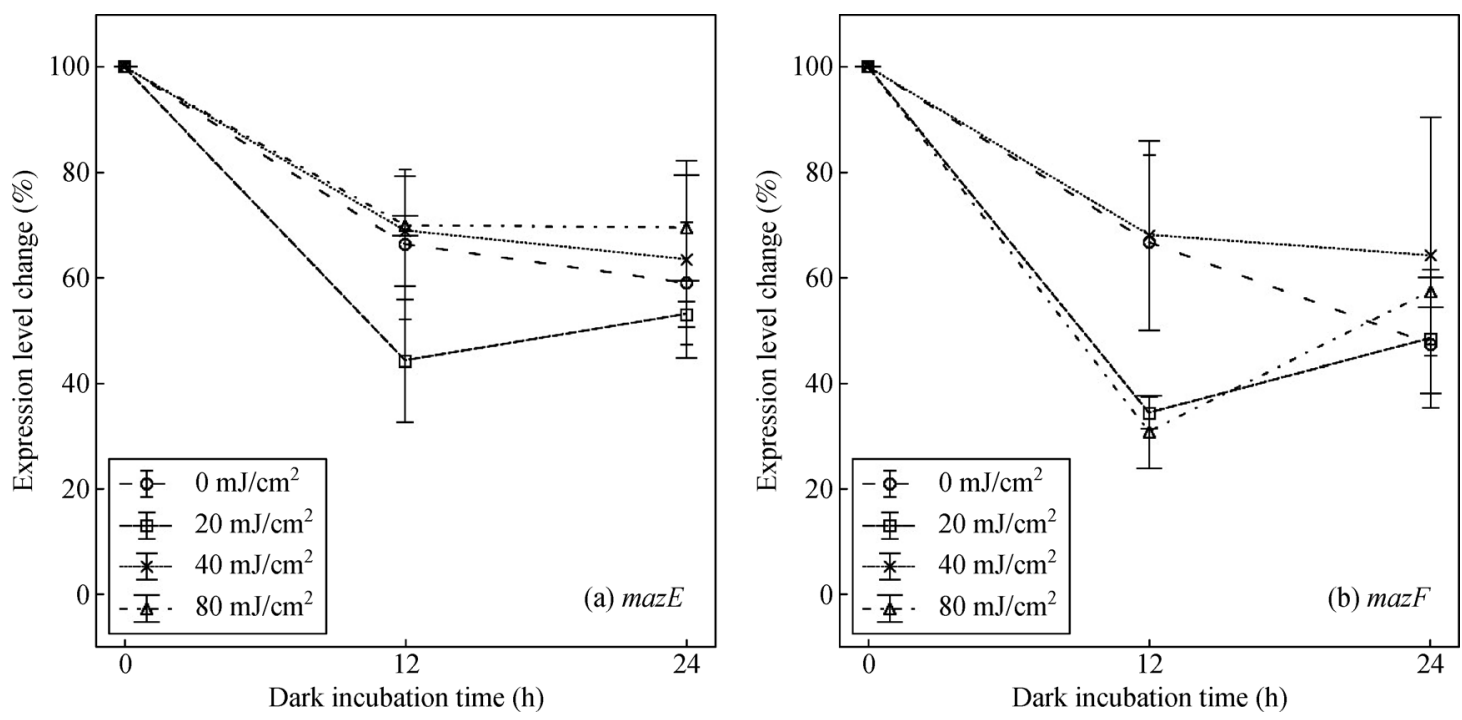

Fig. 4 Expression level changes of PCD system genes after dark incubation: (a) mazE; (b) mazF.

responsible for antitoxins, decreased to $50 \%-90 \%$ of the original expression level at $24 \mathrm{~h}$, whereas the $m a z F$, which is responsible for toxins, decreased to $50 \%-60 \%$ of the expression level at $24 \mathrm{~h}$.

In the "toxin-antitoxin" PCD system, the toxin product is more stable and requires continuous expression of the antitoxin to prevent cells from entering this pathway. Theoretically, only the downregulation of the antitoxin, $m a z E$ in this study, is required for the PCD phenomenon to occur - at least before the toxin is degraded. The results of this study showed that the expression of mazE was indeed downregulated and indicated that cells were undergoing PCD. However, no significant difference was observed between the samples with and without UV irradiation in the downregulation rate of $m a z E$, due to the overlapping confidence intervals. This indicates that the PCD phenomenon encoded by mazEF occurs after dark incubation, but there is no evidence that UV accelerates bacterial entry into PCD. Therefore, in this pathway, cells will proceed to a natural death after UV irradiation but not at a higher speed than those not irradiated by UV.

\section{Conclusions}

This study helps to clarify the effects of UV damage on mRNA and its regulation. The results indicate that UV damages mRNAs with a uniform mechanism and does so 
in a dose-dependent manner. Additionally, because the shape of the UV dose-response curve reflects a concave function, mRNA should be a more suitable viability parameter for lower UV doses. Despite the high level of uncertainty, both the SOS response and PCD systems are believed to be induced after UV irradiation. The expression of the repressor lexA in the SOS response system was upregulated to a lesser extent than was that of $r e c A$; in this manner, UV irradiation induced $E$. coli into the SOS response system more actively. The PCD system regulated by $m a z E F$ was induced through the downregulation of $m a z E$, although UV did not accelerate the PCD process. Therefore, it is implied that UV will more actively induce the dark repair system, and the cells will proceed to death at a rate similar to that of natural decay.

Acknowledgements This research was supported by the Chinese Major National R\&D Project (Nos. 2017ZX07108-003 and 2017ZX07502003). We thank Professor Karl Linden and his group from University of Colorado, Boulder for providing enormous help in experimental support and technique instruction. We thank Professor Wenjun Liu from Tsinghua University who, although no longer with us, had inspired and guided us the students to dedicate to this study and the career that he loved in public health.

\section{References}

Allocati N, Masulli M, Di Ilio C, De Laurenzi V (2015). Die for the community: An overview of programmed cell death in bacteria. Cell Death \& Disease, 6(1): e1609

Bayles K W (2014). Bacterial programmed cell death: making sense of a paradox. Nature Reviews. Microbiology, 12(1): 63-69

Belosevic M, Craik S A, Stafford J L, Neumann N F, Kruithof J, Smith D W (2001). Studies on the resistance/reactivation of Giardia muris cysts and Cryptosporidium parvum oocysts exposed to mediumpressure ultraviolet radiation. FEMS Microbiology Letters, 204(1): 197-203

Blatchley E R 3rd, Dumoutier N, Halaby T N, Levi Y, Laîné J M (2001). Bacterial responses to ultraviolet irradiation. Water Science and Technology, 43(10): 179-186

Blatchley E R, Oguma K, Sommer R (2017). Comment on 'UV disinfection induces a VBNC state in Escherichia coli and Pseudomonas aeruginosa'. IUVA News, 18(3): 12-16

Bolton J R, Linden K G (2003). Standardization of methods for fluence (UV dose) determination in bench-scale UV experiments. Journal of Environmental Engineering, 129(3): 209-215

Craik S A, Finch G R, Bolton J R, Belosevic M (2000). Inactivation of Giardia muris cysts using medium-pressure ultraviolet radiation in filtered drinking water. Water Research, 34(18): 4325-4332

Erental A, Kalderon Z, Saada A, Smith Y, Engelberg-Kulka H (2014). Apoptosis-like death, an extreme SOS response in Escherichia coli. mBio, 5(4): e01426-e14

Fang J, Liu H, Shang C, Zeng M, Ni M, Liu W (2014). E. coli and bacteriophage MS2 disinfection by UV, ozone and the combined UV and ozone processes. Frontiers of Environmental Science \& Engineering, 8(4): 547-552

Gehr R (2015). Comment on "UV disinfection induces a Vbnc state in
Escherichia coli and Pseudomonas aeruginosa". Environmental Science \& Technology, 49(12): 7501

Guo M, Hu H, Bolton J R, El-Din M G (2009). Comparison of low- and medium-pressure ultraviolet lamps: Photoreactivation of Escherichia coli and total coliforms in secondary effluents of municipal wastewater treatment plants. Water Research, 43(3): 815-821

Hazan R, Sat B, Engelberg-Kulka H (2004). Escherichia coli mazEFmediated cell death is triggered by various stressful conditions. Journal of Bacteriology, 186(11): 3663-3669

Hijnen W A, Beerendonk E F, Medema G J (2006). Inactivation credit of UV radiation for viruses, bacteria and protozoan (oo)cysts in water: a review. Water Research, 40(1): 3-22

Jungfer C, Schwartz T, Obst U (2007). UV-induced dark repair mechanisms in bacteria associated with drinking water. Water Research, 41(1): 188-196

Lehtola M J, Miettinen I T, Vartiainen T, Rantakokko P, Hirvonen A, Martikainen P J (2003). Impact of UV disinfection on microbially available phosphorus, organic carbon, and microbial growth in drinking water. Water Research, 37(5): 1064-1070

Linden K G, Hull N M, Rodriguez R A (2015). Comment on "UV disinfection induces a VBNC state in Escherichia coli and Pseudomonas aeruginosa". Environmental Science \& Technology, 49(17): 10750-10751

Liu Y, Zhang Q, Hong Y (2017). Formation of disinfection byproducts from accumulated soluble products of oleaginous microalga after chlorination. Frontiers of Environmental Science \& Engineering, 11 (6): 1

Lu S Y, Wang N Y, Wang C (2018). Oxidation and biotoxicity assessment of microcystin-LR using different AOPs based on $\mathrm{UV}, \mathrm{O}_{3}$ and $\mathrm{H}_{2} \mathrm{O}_{2}$. Frontiers of Environmental Science \& Engineering, 12(3): 12

Murray K E, Manitou-Alvarez E I, Inniss E C, Healy F G, Bodour A A (2015). Assessment of oxidative and UV-C treatments for inactivating bacterial biofilms from groundwater wells. Frontiers of Environmental Science \& Engineering, 9(1): 39-49

Nie X, Liu W, Chen M, Liu M, Ao L (2016). Flow cytometric assessment of the effects of chlorine, chloramine, and UV on bacteria by using nucleic acid stains and 5-cyano-2, 3-ditolyltetrazolium chloride. Frontiers of Environmental Science \& Engineering, 10(6): 12

Oliver J D ( 2000 ). The Public Health Significance of Viable but Nonculturable Bacteria. Boston: Springer, 277-300

Parker J A, Darby J L (1995). Particle-associated coliform in secondary effluents: shielding from ultraviolet light disinfection. Water Environment Research, 67(7): 1065-1075

Pecson B M, Ackermann M, Kohn T (2011). Framework for using quantitative PCR as a nonculture based method to estimate virus infectivity. Environmental Science \& Technology, 45(6): 22572263

Pinto D, Santos M A, Chambel L (2015). Thirty years of viable but nonculturable state research: unsolved molecular mechanisms. Critical Reviews in Microbiology, 41(1): 61-76

Pirnie M, Linden K G, Malley J P, Schmelling D, Usa O O W (2006). Ultraviolet disinfection guidance manual for the final long term 2 enhanced surface water treatment rule: EPA 815-R-06-007. Washington, DC: EPA, 2-8 
Reckhow D A, Linden K G, Kim J, Shemer H, Makdissy G (2010). Effect of UV treatment on DBP formation. Journal- American Water Works Association, 102(6): 100-113

Sinha R P, Häder D P (2002). UV-induced DNA damage and repair: A review. Photochemical \& Photobiological Sciences, 1(4): 225-236

Wang F, Li W Y, Li Y, Zhang J P, Chen J P, Zhang W, Wu X (2018). Molecular analysis of bacterial community in the tap water with different water ages of a drinking water distribution system . Frontiers of Environmental Science \& Engineering, 12(3): 6

Wang N Y, Wang K, Wang C (2017). Comparison of different algicides on growth of Microcystis aeruginosa and microcystin release, as well as its removal pathway in riverways. Frontiers of Environmental Science \& Engineering, 11(6): 3

Xu H S, Roberts N, Singleton F L, Attwell R W, Grimes D J, Colwell R R (1982). Survival and viability of nonculturable Escherichia coli and Vibrio cholerae in the estuarine and marine environment.
Microbial Ecology, 8(4): 313-323

Xu L, Zhang C, Xu P, Wang X C (2018). Mechanisms of ultraviolet disinfection and chlorination of Escherichia coli: Culturability, membrane permeability, metabolism, and genetic damage. Journal of Environmental Sciences-China, 65: 356-366

Zhang S, Ye C, Lin H, Lv L, Yu X (2015). UV disinfection induces a VBNC state in Escherichia coli and Pseudomonas aeruginosa. Environmental Science \& Technology, 49(3): 1721-1728

Zimmer J L, Slawson R M (2002). Potential repair of Escherichia coli DNA following exposure to UV radiation from both medium- and low-pressure UV sources used in drinking water treatment. Applied and Environmental Microbiology, 68(7): 3293-3299

Zimmer-Thomas J L, Slawson R M, Huck P M (2007). A comparison of DNA repair and survival of Escherichia coli O157:H7 following exposure to both low- and medium-pressure UV irradiation. Journal of Water and Health, 5(3): 407-415 